\title{
A AQUISIÇÃO DOS PRIMEIROS PRINCÍPIOS EM ARISTÓTELES
}

\author{
Jaqueline Stefani \\ Universidade de Caxias do Sul
}

Resumo: Examina-se a função da dialética, da indução e da inteligência intuitiva (nous) na aquisição dos primeiros princípios em Aristóteles, enfatizando a análise de Segundos Analíticos | 18, || 19 e Tópicos | 2. Afirma-se que o processo de aquisição requer a indução, que leva a perceber 0 universal nos particulares, a dialética, com seus critérios e testes baseados em endoxa para que, então, os primeiros princípios possam ser apreendidos de forma inequívoca pela inteligência (nous), disposição responsável por conhecer os princípios. Vê-se a indução como o método pelo qual se conhece o universal por meio de particulares, a dialética como instrumento metodológico auxiliando na busca pelos princípios, mais especificamente, pelas definições e o nous como faculdade, movimento noético, que opera de forma infalivel na intuição dos indemonstráveis.

Palavras-chave: Aristóteles, conhecimento, indução, dialética, nous.

Abstract: We examine the dialectical function, of induction and intuitive intelligence (nous) in the acquisition of the first principles in Aristotle, emphasizing the analysis of APo | 18, II 19 and Topics I 2. We assert that the acquisition process requires induction, which leads us to perceive the universal in the particulars, the dialectic, and its criteria and tests based on endoxa, so then the first principles may be apprehended in an unequivocal way by intelligence (nous), disposition responsible for knowing principles. We notice induction as a method whereby we know the universal through the particulars, the dialectic as a methodological instrument supporting in the search of principles, more specifically, through definitions and nous as a faculty, noetic movement, which operates in an unfailing way in the intuition of the unprovables.

Keywords: Aristotle, knowledge, induction, dialectics, nous.

Parece incontroverso que o tema central da famigerada passagem de Segundos Analíticos II 19 é a aquisição dos primeiros princípios. Todavia, 
isso compreende uma gama de problemas mais ou menos relacionados. ${ }^{1}$ Uma questão importante é saber a que tipo de princípios Aristóteles se refere: os comuns (koina), como o princípio da não-contradição (PNC) ou os próprios (idia), como a definição de triângulo para a geometria? Outro problema é o que significa exatamente adquirir um primeiro princípio. Compreender o mero significado de uma proposição, a verdade de uma proposição ou, além da verdade, que uma proposição é causa das outras? Além disso, e essa é a questão central deste artigo, a obra aristotélica apresenta três âmbitos distintos pelos quais se poderia chegar à aquisição dos princípios: a inteligência intuitiva (nous), a dialética e a indução, o que resulta em toda uma tradição de intérpretes ter se dividido sobre esse ponto. ${ }^{2}$ Uma linha de interpretação afirma que a indução é a responsável pela aquisição dos princípios juntamente com os processos que a antecedem, como a percepção e a experiência, e que o papel da dialética é praticamente irrelevante. Outra linha afirma que a inteligência dos princípios se deve à dialética, ao passo que as sensações teriam importância muito reduzida nesse processo. A primeira indicação sobre a questão parece ser o fato de que a divergência estaria no peso atribuído à indução e à dialética com relação à intuição dos princípios e não, propriamente, na discussão sobre a função da inteligência intuitiva (nous). Mas não parece ser

\footnotetext{
1 Um dos problemas é o que Aristóteles entende por "primeiros princípios". Em Segundos Analíticos II 19 $100 \mathrm{~b} 1-5$, tais princípios primeiros não parecem ser proposições, mas conceitos universais. Barnes, em seu comentário aos Segundos Analíticos (2002, p. 259), aponta que: "most commentators have found a deep-seated ambiguity in B 19: its 'principles' vacillate between primitive propositions and primitive terms. [...] much of the language of B 19 suggests that he is speaking of concept-acquisition." Pellegrin (2009, p. 74) diz o seguinte: "Au sens épistémologique, donc, Aristote appelle 'principe' 'une proposition immédiate' (Secondes analytiques I, 2, 72 7 ), mais il n'est pas sûr que les principes soient toujours des propositions. Ainsi les principes premiers de La physique sont la forme, la privation et la matière." A questão, todavia, não será desenvolvida aqui por falta de espaço.

2 Robin Smith, em sua introdução à tradução dos Tópicos (I e VIII), escreve o seguinte sobre a difícil interpretação de Segundos Analíticos II 19: "It has been read as claiming that the starting-points are intuitively self-evident, but this then conflicts with the empiricist sympathies much in evidence in Aristotle's other works. Other scholars instead find an empirical account in the Posterior Analytics and suppose that the knowledge of the first principles simply arises from experience through generalization. But it is difficult to reconcile this with Aristotle's claim that the principles must be better known than what follows from them, especially given his repeated insistence that what we perceive through our sense is known to a lesser degree than the principles and conclusions of demonstrative science. Some have proposed that Aristotle appealed to dialectic to solve this problem. There are several passages (including a crucial text in Top. I.2) which say that dialectical argument, or the art of dialectic, is useful in some way in connection with the first principles on which sciences rest. Perhaps, then, Aristotle supposes that dialectical argument establishes these first principles. Such an interpretation is advanced by Irwin (1988), who argues that a modified variety of dialectic was Aristotle's mature concept of the basic method of philosophy. In my opinion, it is difficult to reconcile such views with Aristotle's frequent assertions that dialectical argument cannot establish anything at all." (2003, p. xvii, xviii).
} 
esse o caso. ${ }^{3}$

Não só a existência desta divergência torna interessante tal análise, como a aparente incompatibilidade tanto entre indução e inteligência intuitiva, quanto entre dialética e inteligência intuitiva, pois ambas, dialética e indução, são aparentemente falíveis ao passo que a inteligência intuitiva não. Veja-se, por exemplo, a natureza das premissas utilizadas na dialética. Tal natureza não parece compatível com a infalibilidade da inteligência intuitiva, pois, ainda que se reconheça a importância da dialética à ciência aristotélica, a discussão sobre opiniões reputadas parece distante demais da função exigida pelo âmbito responsável por apreender os primeiros princípios; ademais, de todas as formas pelas quais é possível obter conhecimento verdadeiro, algumas nunca incorrem em erro, como é o caso do conhecimento científico (episteme), da inteligência (nous) e da sabedoria filosófica (sophia), ao passo que a opinião (doxa), por exemplo, admite a falsidade. ${ }^{4}$ Nas ciências deve-se conhecer as essências próprias ao gênero para usá-las como princípios da demonstração. ${ }^{5}$ Todavia, dessas essências não há demonstração, mas um silogismo dialético que conduz aos princípios. ${ }^{6}$ Ora, se a dialética tem como ponto de partida opiniões, ainda que reputadas (endoxa), como pode ela ser a responsável pela apreensão dos princípios juntamente com a inteligência intuitiva, aquela faculdade que nunca incorre em erro?

Por outro lado, escreve Aristóteles em Segundos Analíticos I 18 81a 35 e II 19 100a 15, que o conhecimento dos primeiros princípios é obtido por indução (epagoge), mas sabe-se também que o conhecimento dos princípios é o mais certo que se pode ter. No que tange à indução, Aristóteles afirma ora que basta a observação de um caso exemplar apenas, como em Tópicos VIII 14 163b 10, ora que é necessário proceder por meio de uma indução por enumeração completa, como em Primeiros Analíticos II $2368 \mathrm{~b} 25$. No entanto, se em uma dedução as premissas são verdadeiras, a conclusão é necessariamente verdadeira, o que não ocorre na indução em que o argumento pode conter premissas verdadeiras e conclusão falsa.

\footnotetext{
${ }^{3}$ Como bem aponta Barnes em seu comentário à tradução dos Segundos Analíticos (2002, p. 259): "The principles are apprehended by "induction" (epagoge) in an honest empiricist way; but they are also grasped by nous, or "intuition" as it normally translated, in the easy rationalist fashion. It is a classic problem in Aristotelian scholarship to explain or reconcile these two apparently opposing aspects of Aristotle's thought".

${ }^{4}$ Cf. Segundos Analíticos II 19 100b 5-10.

${ }^{5}$ Como afirma Barnes, em sua introdução à tradução dos Segundos Analíticos: "The axioms of any science, it supposes, must be (or at least include) definitions or statements of essence; and its main burden is to ask how these definitions are to be elicited and exhibited". (2002, p. xiii).

${ }^{6} \mathrm{Cf}$. Segundos analíticos II 8 93a 15.
} 
Como o conhecimento infalível dos primeiros princípios pode ser adquirido por indução e quantas observações são necessárias para se obter uma conclusão com alguma garantia epistêmica?

O silogismo demonstrativo é o instrumento pelo qual se obtém conhecimento científico, no sentido aristotélico do termo. Em Segundos Analíticos I 2 71b 20, são apresentas as características necessárias às premissas de tais silogismos, as quais devem ser: i) verdadeiras, pois é impossível conhecer cientificamente o que não é o caso; ii) primeiras e indemonstráveis, dado que o que pode ser demonstrado não é primeiro e o que é primeiro deve ser autoevidente e incausado; iii) imediatas, pois do contrário o pensamento resultaria em uma redução ao infinito e iv) mais conhecidas que a conclusão, anteriores à conclusão e causa da conclusão - anteriores e mais conhecidas tanto no sentido da essência, pois é preciso saber o que a coisa é, quanto no da existência, pois é preciso saber que ela é. Além disso, a conclusão resulta das premissas primárias, primeiros princípios imediatos e absolutamente anteriores. ${ }^{7}$ Tais premissas exprimem causalidades imediatas e são, por isso, indemonstráveis.

À ciência são necessários dois tipos de princípios: os comuns a todas as ciências e os próprios a cada uma delas. Os próprios são ou definições (se apresentam a essência), ou hipóteses (se assumem a existência), o que resulta na distinção entre conhecer que algo é e conhecer o que algo é. No que tange à ciência, parece que a função de cada um deles é distinta: os próprios figuram como premissas do silogismo; os comuns são pressupostos e não aparecem no silogismo como premissas diretamente. ${ }^{8}$ Os princípios próprios são aquelas proposições que se constituem no conhecimento prévio necessário ao conhecimento científico e se referem à existência de algo e/ou à sua essência. Proposições que apresentam a essência são definições e, tendo em vista que a definição é um tipo de princípio próprio e que dos princípios não se deve reclamar a causa (requerer uma demonstração), resta evidente que de proposições que apresentam a essência não se deve requerer demonstração.

A discussão sobre como se estabelece uma definição parece central à dialética aristotélica, tal como se vê nos Tópicos. A maior parte da obra tem por objeto a problemática em torno dos predicáveis e a apresentação dos

\footnotetext{
${ }^{7}$ Cf. Segundos Analíticos I 272 a.

${ }^{8}$ Cf. Segundos Analíticos I 11 77a 25.
} 
lugares comuns que devem ser seguidos na elaboração de definições. A dialética apresenta três distintas utilidades, segundo Tópicos I 2, 101a 25101b 5: i. exercitar o intelecto, sendo, pois, um uso de tipo particular; ii. capacitar para se sair bem nas disputas casuais (públicas), pois parte de opiniões aceitas pela maioria e, portanto, de opiniões que são familiares ao interlocutor, auxiliando na conversação em geral; e iii. suscitar dificuldades significativas sobre ambas as faces de um problema filosófico, o que possibilita que se detecte mais facilmente a verdade e o erro nos mais variados problemas. Haveria, ainda, outra utilidade podendo ser considerada uma subdivisão da terceira, que consiste em tomar a dialética como processo que abre o caminho à apreensão dos princípios primeiros de cada ciência. Essa última utilidade, inclusive, é tomada por Aristóteles como a característica que mais acertadamente convém à dialética, constituindo-se em sua utilidade mais apropriada.

Na dialética são apresentadas hipóteses para um problema qualquer; em seguida, a investigação procurará refutar uma das proposições da aporia de forma que a outra restará como a resposta mais acertada ao problema, com base tanto nos princípios comuns, quanto em endoxa. Assim, o dialético tem a capacidade de refutar qualquer tese respaldado em regras lógico-formais ${ }^{9}$ e na observância de regras para a conduta e avaliação dos debates. $\mathrm{O}$ respaldo em regras lógico-formais se dá seja com base nos princípios comuns e pode, assim, identificar incoerências argumentativas que o interlocutor venha a apresentar se ele assumir uma tese, por exemplo, cujas consequências resultem em contradição. Tal teste dialético com base nos princípios comuns é de grande auxílio à ciência, por possibilitar que se perceba o verdadeiro e o falso, conforme Aristóteles atesta no terceiro uso da dialética. ${ }^{10}$

A opinião discutida nos Tópicos é uma opinião reputada (endoxa), aceita por todos, pela maioria ou pelos mais sábios. Em tais opiniões, há uma explicitação de natureza quantitativa (muitos ou todos) e qualitativa (pessoas reconhecidas como sábias, como conhecedoras afamadas dos assuntos em questão), que faz com que tenham força importante. Aristóteles recorre ora à opinião da maioria das pessoas e dos sábios, ora à de algum sábio, especificamente, mas sempre a opiniões que carregam, de alguma forma, um peso persuasivo: seja pelo grande número de pessoas que a 
proferem, seja pela importância de quem a profere. $^{11}$ Tais opiniões reputadas são fundamentadas e, portanto, respeitáveis, por serem proposições corretas com base naquilo que atestam os especialistas, todos ou a maioria. As opiniões reputadas podem ser verdadeiras, mas não o são necessariamente. $\mathrm{O}$ argumento demonstrativo, por outro lado, parte de premissas verdadeiras e primeiras. $^{12}$

Aristóteles por vezes é taxativo sobre a diferença entre o método científico e o dialético, mas, por vezes, atribui à dialética responsabilidade ímpar no tocante ao alcance dos primeiros princípios. Tal dificuldade na compreensão da natureza e da função da dialética produziu diferentes interpretações por comentadores da obra aristotélica. No início da década de 60 , surge a tendência a analisar o método que o próprio filósofo empregou em suas investigações. Haveria uma diferença importante entre o método científico descrito nos Analíticos e o método que Aristóteles teria utilizado em seus tratados "científicos". Se se tomar a teoria aristotélica da ciência proposta nos Analíticos, ciência é conhecimento certo resultante do método silogístico demonstrativo, o qual depende da verdade, da imediatez e da necessidade de suas premissas. É igualmente indispensável a todo o conhecimento que se quer científico, que ele apresente a causa, a razão, o porquê daquilo que se demonstra ser daquele modo e não de outro. Todavia, o procedimento adotado por Aristóteles em seus tratados científicos não parece seguir tais preceitos, no sentido de ser um conhecimento que parta de premissas primeiras, as quais são princípios indemonstráveis, e que contenha a característica de verdade necessária.

Segundo Le Blond, em Lógica e método em Aristóteles, Aubenque, em O problema do ser em Aristóteles, e Guéroult, em Lógica, argumentação e história da filosofia em Aristóteles, o método que Aristóteles utiliza em suas exposições, e que é por ele praticado inclusive na investigação dos princípios (na Física e na Metafísica), não é o científico teorizado nos Analíticos, nem o indutivo que parte de uma análise de observações empíricas particulares, mas o dialético. Entretanto, não se trata de qualquer parte do método dialético, mas aquele entendido no terceiro uso indicado nos Tópicos, a saber, no sentido da apresentação de ambas as faces

\footnotetext{
11 Smith, em sua introdução à tradução dos Tópicos (I e VIII), escreve o seguinte: "He says that the premisses used in dialectic must be endoxa, 'acceptable'. Now, 'acceptable' is a relative term: to be acceptable is to be to someone, or to some type of person. In several places Aristotle gives us a short list of general types. Some premises are acceptable to everyone; some are acceptable to the majority of people; some are acceptable to 'the wise', others to most of the wise, and other to specific well-known sages (and their schools)". (p. xxiii).

${ }^{12}$ Cf. Tópicos I 1 100a 25-100b 25.
} 
de um problema e análise das teses opostas, para que se possa avaliar com maior precisão tais oposições e mais acertadamente distinguir o verdadeiro do falso. Tal uso do método dialético seguiria, inclusive, os preceitos apresentados pelo próprio Aristóteles nos Tópicos e trataria de apresentar e examinar, criticamente, as hipóteses que foram apresentadas por outros antes dele.

Berti (2010), retomando a teoria de Guéroult e desenvolvendo-a, sustenta teses ousadas a esse respeito, afirmando não só que o método usado por Aristóteles na maioria de suas obras, inclusive as científicas, é o dialético, mas que o caráter dialético de tal método tem um valor científico para Aristóteles: "A 'dialeticidade' da historiografia filosófica de Aristóteles não exclui a possibilidade de que se chegue por meio dela a resultados que o filósofo teria considerado 'científicos', ou seja, dotados de verdade e necessidade”. (BERTI, 2010, p. 206). O método dialético empregado por Aristóteles teria a característica de um diálogo onde duas hipóteses são apresentadas de forma oposta, o que permite que se avalie com clareza as dificuldades decorrentes delas e, assim, se apresente a hipótese não rechaçada como solução da aporia. Tal método possibilita que sejam colocadas frente a frente as opiniões opostas sobre um assunto específico qualquer. É um silogismo disjuntivo em que se propõe que, se dos disjuntos apresentados um for demonstradamente falso, o outro disjunto será, consequentemente, verdadeiro, tendo por base tanto o PNC quanto o princípio do terceiro excluído.

Concorda-se parcialmente com Berti. Compartilha-se a ideia sobre o uso do método aporético por Aristóteles em vários de seus tratados. Por exemplo, em Metafísica B 1 995a 20-995b 5, Aristóteles aponta a aporia como um caminho que a filosofia primeira deve seguir para chegar à solução de problemas, mas tal caminho não é ciência e consiste em um movimento prévio, preexistente à ciência. Fica claro que o exame ao qual Aristóteles se refere, por meio do qual são analisadas soluções contrastantes sobre um problema, é um exame dialético, é uma "espécie de dialética".13 Em segundo lugar, que tal exame dialético das dificuldades seja necessário para que se chegue a boas soluções, inclusive no tocante à filosofia primeira, é igualmente não problemático. Por último, que quem não realiza tal exame dialético, avaliando as hipóteses contrastantes e que já foram apresentadas por outros como soluções possíveis a um problema qualquer, equivale a alguém que está perdido em um caminho com várias encruzilhadas e não faz a menor ideia de qual direção deve tomar.

${ }^{13}$ Cf. Refutações Sofísticas 11 171b 1-5. 
O uso do argumento disjuntivo por Aristóteles aparece em muitas de suas obras e com função bem específica, a qual não se limita a mero recurso estilístico. É o próprio Aristóteles quem afirma a importância desse tipo de argumento $;^{14}$ dos opostos, se um é falso, o outro deve ser verdadeiro e viceversa, por força lógica. O segundo passo argumentativo de Aristóteles é, na maioria dos casos, apresentar as consequências absurdas que derivam de uma dessas proposições opostas para, então, demonstrar o absurdo da proposição propriamente dita e, assim, demonstrar sua falsidade por absurdo; assim, a outra proposição resta evidente. É ainda na Metafísica (I 993b 1-5) que se encontra a referência às opiniões como algo de grande importância, inclusive no conhecimento da verdade, especialmente na importância de um levantamento das opiniões dos filósofos predecessores.

Aristóteles investiga se as opiniões comuns estão de acordo com o resultado de sua análise filosófica. A harmonia entre ambas (opiniões e análise) será uma confirmação da precisão do raciocínio filosófico, razão pela qual Aristóteles tenta mostrar a verdade de suas conclusões filosóficas, comparando-as com as opiniões correntes. ${ }^{15}$ Ainda em Metafísica (Z 2 e Z 4, 1029a 30-1029b 5), vê-se Aristóteles utilizando a dialética e partindo, portanto, de opiniões reputadas, na construção de suas afirmações sobre o número e a natureza da substância. Em geral, quando Aristóteles apresenta proposições que são de opinião comum ou que todos admitem ou com as quais estão de acordo, tais proposições serão acatadas igualmente por ele. ${ }^{16}$ Função argumentativa diferente ocorre quando Aristóteles apresenta filósofos que divergem sobre determinado assunto, e que ele próprio irá contestar como no caso de Metafísica Z 2 1028b 15-30. No De Anima, também é possível ver Aristóteles utilizando a dialética como em I $2403 \mathrm{~b}$ 20.

Entretanto, para Berti, quando Aristóteles apresenta os diálogos entre sua tese e as teses de outros filósofos, suas conclusões teriam para Aristóteles um caráter de absoluta 'cientificidade', no sentido aristotélico do termo. Além disso, afirma que haveria uma parte da dialética útil apenas

\footnotetext{
${ }^{14}$ Cf. Metafísica I 5 1055b 30-35.

${ }^{15}$ Segundo Verbeke, em Philosophie et conceptions préphilosophiques chez Aristote, Aristóteles faz uso de opiniões, distinguindo aquelas que são aceitáveis das que não são. Em algumas áreas, como na ética, devemos considerar apenas as opiniões dos sábios ou de pessoas dignas de consideração. Aristóteles acredita que não é necessário fazer um estudo exaustivo de todas as opiniões em todos os casos, mas devem-se considerar aquelas mais persistentes ou melhor justificadas. Verbeke afirma que Aristóteles quer colocar sua filosofia em harmonia com as opiniões universalmente prevalentes ou geralmente aceitas, especialmente se elas são antigas e reputadas. Para Aristóteles, segue Verbeke, cada um tem sua própria contribuição a dar para o desvelamento da verdade.

${ }_{16}$ Tal recurso pode ser visto novamente em outra parte da Metafísica H 2 1042b 10.
} 
para habilitar os contendentes em um debate e, nesse sentido, a discussão de opiniões, com o objetivo de disputar ou refutar, é o cerne da questão, e outra parte mais "científica", no sentido aristotélico, cujo objetivo final é uma investigação para se atingir a verdade. Tomar a parte da dialética "mais científica" - seja lá o que isso for - como parte da ciência, por ela possibilitar que se chegue a conhecimentos verdadeiros, ou afirmar que para Aristóteles tal processo "possui um caráter de absoluta "cientificidade", é problemático, pois a ciência tem por método a demonstração, o silogismo demonstrativo e não qualquer argumento que possibilite que se atinja a verdade ${ }^{17} \mathrm{O}$ que é científico é o conhecimento obtido por demonstração, e os primeiros princípios, premissas do silogismo científico, pertencem ao conhecimento preexistente e não são científicos simplesmente porque não são, eles mesmos, obtidos por demonstração. Assim, os resultados obtidos pelo método dialético, ainda que possam ser verdadeiros, não se caracterizam como ciência, pois o método da ciência é a demonstração e o da dialética é a investigação.

A dialética auxilia, dentre outras coisas, no processo de conhecer os princípios necessários à ciência, e o procedimento dialético se efetiva através de racionalidade crítica e investigativa, ao passo que a ciência produz o conhecimento da conclusão e não das premissas do argumento. Assim, a ciência não objetiva o conhecimento dos princípios, ao contrário, ela os supõe. Ora, uma coisa é de onde se parte, outra bem distinta é aonde se chega, e há uma diferença intransponível entre esses dois momentos (de partida e de chegada) se se refere à ciência, que é demonstrativa, e se se refere à aquisição de suas premissas. As premissas, i.e. de onde se parte para concluir alguma coisa, são necessariamente verdadeiras no conhecimento científico, mas na dialética, não, ainda que possam ser verdadeiras. Que o uso da dialética para chegar aos princípios de cada ciência, especificada no terceiro uso por Aristóteles, seja útil à ciência, é evidente. Todavia, perguntar não é propor e, na premissa dialética, faz-se uso da pergunta, de uma interrogação disjuntiva, para daí assumir uma de ambas como uma suposição, ao passo que na premissa demonstrativa propõe-se algo de tal forma que não há alternativa em tal proposição, mas necessidade. Dizer que a dialética (ou uma parte dela) é científica, nesse sentido, equivaleria a dizer que a indução é científica, pois a indução é tão útil à ciência quanto o é a dialética.

Veja-se o que diz Aristóteles nas esclarecedoras palavras finais dos Segundos Analíticos: "Como toda ciência tem lugar por um raciocínio, não

${ }^{17} \mathrm{Cf}$. , por exemplo, Tópicos I 1 100a 25-30. 
haverá ciência dos princípios. Mas, uma vez que nada pode ser mais verdadeiro do que a ciência a não ser o intelecto, haverá intelecção dos princípios: (...) A demonstração não é princípio de demonstração, nem a ciência princípio da ciência." (II 19, 100b 10). Ora, o princípio de uma demonstração são suas premissas, as quais são obtidas com algum auxílio da argumentação dialética. Aristóteles diz claramente que tanto o conhecimento dos princípios é diverso do conhecimento científico, quanto o resultado de um é diferente do resultado do outro. A mesma ideia pode ser encontrada em Metafísica $\Gamma$ 6, 1011a 10-15, na afirmação de que são diferentes o princípio da demonstração e a conclusão da demonstração.

A importância do levantamento das opiniões dos filósofos, dos sábios ou mesmo de pessoas que são reconhecidamente especialistas em alguma área de conhecimento é atestada por Aristóteles teoricamente e, igualmente, na prática, pois assim ele delas se utiliza largamente. Tal levantamento e exame dessas opiniões reputadas têm grande relevância, pois o verdadeiro e o falso são mais facilmente perceptíveis. Da mesma forma é importante que se realize o exame dos diferentes sentidos de um termo, função própria ao dialético, na busca por conhecimentos verdadeiros. A Metafísica é a ciência por excelência cuja finalidade é a busca pelos primeiros princípios. $\mathrm{Na}$ Metafísica, Aristóteles utiliza largamente a dialética exatamente porque a dialética é indispensável no provimento dos primeiros princípios, de forma que tal uso, por Aristóteles, não contraria de forma alguma os preceitos estabelecidos nos Analíticos. Antes, tal uso corrobora a distinção entre ciência e dialética feita por Aristóteles nos Analíticos e nos Tópicos, apresentando o uso dialético como método auxiliador no provimento dos princípios. Em uma investigação em que alguém se propõe a conhecer algo, há dois processos envolvidos: o primeiro diz respeito ao conhecimento de definições, que vão figurar como premissas do silogismo demonstrativo, e o segundo diz respeito à conclusão do silogismo científico. O conhecimento das premissas do silogismo demonstrativo é obtido por meio de percepção sensível, indução, dialética e intelecto e não é, evidentemente, conhecimento científico. É somente ao conhecimento resultante do silogismo demonstrativo que Aristóteles chamará de "conhecimento científico" de forma estrita. Nesse ponto Berti parece se equivocar ao afirmar que a dialética é necessária não só na aquisição dos princípios, mas igualmente nas demonstrações científicas, participando tanto do processo ascendente quanto do descendente. ${ }^{18}$

\footnotetext{
${ }^{18}$ É certo, todavia, que existem argumentos dedutivos na dialética e, no sentido da dedução dialética,
} poder-se-ia pensar em sua função em sentido descendente. Entretanto, mesmo nesse sentido, a 
"Conhecimento científico", no sentido estrito do termo, é a expressão utilizada por Aristóteles para se referir apenas ao resultado do silogismo demonstrativo, não abarcando o conhecimento ascendente e investigativo relacionado às premissas. ${ }^{19}$ Além disso, não se encontra nos textos de Aristóteles a divisão da dialética por graus de cientificidade. Por outro lado, vê-se a dialética como um conjunto sistemático e unitário de regras, além de considerá-la indispensável para o momento que antecede o conhecimento científico, mas não como parte dele.

A dialética faz parte do processo de crítica, do caminho que conduz aos princípios de toda investigação, baseada em opiniões reputadas e na construção de argumentos orientada pelos lugares comuns. É através do processo crítico de prova, empreendido pela dialética, que é possível transformar opiniões reputadas em problemas, por meio de argumentação crítica capaz de pôr em exame tais opiniões defendidas por sábios e filósofos. ${ }^{20}$ Tal processo, que tem por objetivo atingir os princípios próprios, faz uso tanto de observações empíricas quanto dos endoxa, utilizando, em cada caso, do que mais e melhor se dispõe sobre aquele assunto para aquele que investiga. ${ }^{21}$ Os primeiros princípios próprios a cada ciência são

dialética é tomada como discussão das provas, e, se requer "discussão", então não se impõe com necessidade e não é ciência.

${ }^{19}$ Em Segundos Analíticos I 3 72b 15-20, há uma passagem polêmica em que Aristóteles afirma que nem toda ciência é demonstrativa, referindo-se diretamente ao conhecimento dos princípios primeiros; polêmica, pois tantas vezes ele dissera que toda a ciência é demonstrativa. É possível ver que há um uso do termo episteme lato e outro estrito. O sentido lato compreenderia, além da ciência demonstrativa, uma ciência anapodíctica, a qual teria a função de apreender os primeiros princípios. Mas é digno de nota que o uso do termo episteme, em seu sentido lato, não é nem o mais rigoroso nem o mais corrente em Aristóteles. É apenas a partir dessa compreensão dos termos e de seus usos por Aristóteles, que se pode fazer uma leitura sem estranhamentos, especialmente nas duas afirmações feitas nos Segundos Analíticos: "nem toda a ciência [episteme] é demonstrativa" (I 3 72b 15) e "eu chamo 'demonstração' um silogismo científico" (I 271 b 15).

20 Veja-se, sobre isso, Porchat (2001, p. 371).

${ }^{21}$ Posição semelhante é a de Robin Smith que, em sua introdução à tradução dos Tópicos (I e VIII), escreve o seguinte: "Instead, I see dialectical argument as making more limited, though important, contributions to the acquisition of knowledge of scientific principles through its ability to reveal the contradictions implied by a collection of propositions. (...) Like Socrates, Aristotle thinks that the first step in acquiring philosophical wisdom is the realization that our received wisdom is flawed, that there are puzzles and problems implicit in what we took to be most familiar and obvious. (...) and dialectical argument is the tool that reveals these inconsistencies to us. Thus the Aristotelian practice of 'working through the puzzles', exploring the inconsistencies among the received opinions about a subject, is a direct descendant of Socratic refutation. Dialectical argument is, then, the first mover of philosophical inquiry because it removes us from our intellectual complacency and shows us that there are problems to be solved. Moreover, in revealing just what the puzzles are that must be solved, it sets the agenda for philosophical inquiry and gives a necessary condition for the adequacy of a theory. (...) This suggests a relatively conservative methodology for philosophical inquiry: revise whatever beliefs you have so as to eliminate inconsistencies with the minimum disturbance of other beliefs." (2003, p. xviii). 
conhecidos dialeticamente através de um trabalho crítico de revisão e substituição das predicações em proposições definitórias, até que se eleja a melhor, por meio do raciocínio e com o auxílio dos tópicos, e se encontre o princípio próprio procurado. Uma vez de posse do princípio, o investigador passa a se mover não mais no âmbito dialético, mas no âmbito do conhecimento científico.

Todavia, se a dialética é apresentada como o método pelo qual se apreendem os indemonstráveis, em outras passagens de textos aristotélicos quem ocupa esse lugar é a indução. Essa é uma questão distintiva importante, pois ainda que uma parte da dialética opere indutivamente, nem toda a dialética é indutiva e nem toda a indução é dialética.

\section{II}

O termo "indução" é utilizado por Aristóteles com significações mais ou menos distintas, ainda que, ao que parece, uma característica seja comum a todas elas: um raciocínio é indutivo se e somente se infere de casos particulares (ou de menor extensão) uma conclusão geral ou de maior extensão. ${ }^{22}$ Aristóteles relaciona a indução (epagoge) e aquilo que é mais conhecido em relação a nós, com a dedução e aquilo que é mais conhecido em si mesmo em Primeiros Analíticos II 23 68b 30-35, afirmando que o silogismo dedutivo é anterior e mais conhecido por natureza, enquanto o silogismo indutivo é anterior e mais conhecido para nós. ${ }^{23} \mathrm{O}$ objetivo do conhecimento é cumprido quando as duas esferas (o mais conhecido para nós e o mais conhecido por natureza) coincidem, i.e. quando a percepção do particular - que é o mais conhecido para nós e anterior - torna-se o conhecimento dos universais, o mais conhecido em si mesmo, o absolutamente conhecido. $^{24}$ É clara a oposição aristotélica entre investigação e ciência. A primeira se constitui em um processo ascendente, do particular ao universal, do conhecimento do quê ao conhecimento do porquê; a segunda é um saber acabado, descendente, do universal ao

\footnotetext{
${ }^{22} \mathrm{Cf}$. introdução de Ross à edição grega dos Analíiticos, p. 47, 48.

${ }^{23}$ Cf. Metafísica $\Delta 111018 \mathrm{~b} 30$.

${ }^{24}$ Segundo Porchat: "Há ciência quando o conhecimento humano supera a sua espontaneidade para situar-se na perspectiva nova de uma absoluta coincidência com a mesma ordem do ser. Porque o mais conhecido, para nós, agora, uma vez operada a 'inversão' que torna a ciência possivel, é o mais conhecível em si e por natureza, por isso podemos falar do 'mais conhecido por natureza e em sentido absoluto', como característica das premissas científicas. E podemos dizer, igualmente, que a anterioridade absoluta segundo a essência e a causa tornou-se, agora, uma anterioridade para nós." (2001, p. 119).
} 
particular. ${ }^{25}$ A indução parte de casos particulares e do que é mais conhecido. Ora, quando se parte do que é particular e mais conhecido, se parte daquilo que é acessível aos sentidos e, portanto, daquilo que é mais familiar e mais facilmente admitido como correto. A indução deve ser aceita, a menos que aquele que a rejeite apresente um contraexemplo. ${ }^{26}$

Aristóteles, na Ética Nicomaquéia I 7 1098b 1-5 apresenta uma resposta que, em um primeiro momento, parece estranha para o problema da apreensão dos princípios, ao afirmar que, no caso dos princípios, alguns são apreendidos por sensação, outros por indução e outros por hábito. Indução, sensação e hábito parecem ser maneiras distintas de apreensão dos princípios. Em primeiro lugar, é importante ressaltar que esse trecho se encontra no livro I da Ética onde Aristóteles discute o conhecimento dos princípios e afirma que não se deve buscar igual precisão em todos os assuntos nem exigir o conhecimento da causa em todos os casos. No caso dos princípios, não se deve buscar a causa, a saber, não se deve querer demonstrá-los cientificamente, tendo em vista que os princípios são o ponto de partida e jamais a conclusão de uma demonstração. Em segundo lugar, o hábito é, nesse caso, compreendido como a última instância da experiência. Sendo assim, parece que essa passagem pode ser interpretada do seguinte modo: é pela sensação que se inicia o processo de apreensão indutiva, de forma que ela não é uma via diferente pela qual se tem acesso aos princípios, quando se diz que uns são apreendidos por indução e outros por sensação. Com o hábito ocorre algo semelhante, pois ele é a última forma da experiência, ou o que vem depois dela. Assim, parece que indução, sensação e hábito são antes momentos distintos da apreensão dos princípios que propriamente formas diferentes ou faculdades distintas de apreendê-los. A sensação, desse modo, torna-se indispensável ao momento que antecede o conhecimento científico, de forma que sem ela não há indução e, portanto, não é possível o conhecimento dos universais. A dialética, por outro lado, configura-se como um processo indispensável, exatamente porque é por meio dela que se pode trabalhar com opiniões conflitantes. Entretanto, a percepção sensível e a indução precisam de maiores explicações para que se perceba tal relação.

\footnotetext{
${ }_{25}$ Sobre isso, diz Angioni em comentário à Física (2009, p. 69): "o mais cognoscível para nós é 0 princípio de descoberta; o mais cognoscível por natureza é o princípio da demonstração que explica os fatos por suas causas apropriadas. (...) aquilo que é mais cognoscivel por natureza e serve como princípio da demonstração são as definições primeiras".

${ }^{26}$ Cf. Tópicos VIII 2 157a 30-35.
} 
Para Aristóteles o conhecimento dos princípios não é inato, pois seria absurdo se, ao nascer, o conhecimento mais elevado de todos - aquele dos primeiros princípios - já estivesse em nós, sem que soubéssemos ou tivéssemos dele consciência. Todavia, Aristóteles discorda também da perspectiva na qual não há nada que seja inato no tocante à apreensão dos princípios, pois, dessa forma, nada poderia vir a ser conhecido. ${ }^{27}$ Aristóteles é ponderado ao afirmar que o que existe de inato é a faculdade (dunamis) capaz de discernimento através da qual é possível ter início o processo de conhecimento dos princípios. $^{28}$ Tal faculdade é a percepção sensível (aisthesis). Colocar a percepção nesse lugar de destaque causa um estranhamento inicial, afinal, Aristóteles atestou tantas vezes que não é possível adquirir conheci-mento científico pela percepção, pois a percepção refere-se aos particulares e a ciência aos universais, como em Segundos Analíticos I 31 87b 25-35, De Anima II 5 417b 20, Ética Nicomaquéia II 9 $1109 \mathrm{~b} 20$ e III 5 1113a 1.

Como resolver tal impasse sobre o lugar ou a importância da percepção no conhecimento científico? Em primeiro lugar, parece que esse impasse é apenas aparente. Dizer que é impossível ter conhecimento científico pela percepção não significa dizer que a percepção seja dispensável no provimento dos primeiros princípios, os quais são necessários ao conhecimento científico. O que parece impossível, em Aristóteles, é ter ciência apenas por percepção. Isso porque são percursos diferentes: um é ascendente e vai do particular ao universal e o outro é descendente e vai do universal ao particular. Ao primeiro é necessária a percepção, mas não suficiente. Ao segundo, a partir do momento em que já temos as premissas de onde a conclusão será demonstrada, a percepção não tem participação alguma. Por isso Aristóteles afirma que não há ciência pela percepção. Todavia, sem o processo ascendente, o descendente não pode acontecer; o ascendente, em todo o caso, não é ciência.

A experiência ${ }^{29}$ retém a percepção em uma imagem mental e, ainda que restrita ao conhecimento de particulares, é capaz de propiciar ao raciocínio a elaboração da síntese desses particulares, processo essencial possibilitado pela indução, que alcança os princípios. ${ }^{30} \mathrm{Na}$ conhecida passagem II 19 dos Segundos Analíticos encontra-se ideia muito semelhante sobre experiências que, quando repetidas, possibilitam conhecer os

\footnotetext{
${ }^{27}$ Cf. Segundos Analíticos II 19 99b 30-35.

${ }^{28}$ Cf. Segundos Analíticos II 19 100a 10.

${ }^{29} \mathrm{Cf}$. Primeiros Analíticos I 30 46a 15-25.

30 Cf. Ética Nicomaquéia VI $31139 \mathrm{~b} 30$.
} 
universais. ${ }^{31} \mathrm{~A}$ importância atribuída à percepção sensível é tanta que, como diz Aristóteles, se falta um dos sentidos, desaparece uma ciência, necessariamente. ${ }^{32}$ Tendo em vista que o conhecimento se produz ou por demonstração ou por indução, e que a percepção é necessária à indução e a indução é necessária à aquisição das premissas pelas quais a demonstração opera, conclui-se que, sem percepção, ambos os tipos de conhecimento (tanto os indutivos quanto os demonstrativos) são impossíveis. É por indução, então, que se obtém o princípio de um conhecimento universal, como Aristóteles atesta, inclusive, na Ética Nicomaquéia VI 3 1139b 25-30. A experiência possibilita à dialética abrir o caminho que conduzirá aos primeiros princípios de cada ciência por meio da indução, tendo em vista que é a indução a responsável por fazer o raciocínio perceber, em uma enumeração de casos particulares, algo que pertença a toda essa enumeração. Mas, se o conhecimento dos primeiros princípios é o mais certo que se pode ter, então como ele pode ser adquirido por indução?

Em Segundos Analíticos II 19 100b 1-5, Aristóteles apresenta a indução como o raciocínio que conclui universalmente partindo de percepções particulares. Noção semelhante é apresentada em Tópicos I 12 105a 10-15, em I 18 108b 10 e em VIII 1 156a 5 e também em Segundos Analíticos I 1 71a 1-10. É através da indução que a percepção dos particulares produz o universal. ${ }^{33}$ Por meio da indução se alcança o conhecimento do particular como um caso da categoria universal que o contém, como componente de uma classe universal. Mas quantas observações são necessárias para concluir, acertadamente, um universal?

Nesse ponto, tal método indutivo requer atenção especial. O número de casos particulares que, em geral, devem ser observados, e que permite que a inteligência reconheça o universal, varia conforme a capacidade do observador. Tal capacidade é a perspicácia ou vivacidade de espírito, que

\footnotetext{
${ }^{31}$ Assim se expressa Barnes, em comentário à tradução dos Segundos Analíticos (2002, p. 264), em especial à II 19: "What is experience? And does the experienced man formulate any sort of universal proposition? Experience depends on the presence of many memories of the same thing (Met A I, 980b29). We might, then, imagine the experienced man saying something like: 'All the Bs l've ever come across have been A' (cf. A I, 71a34, for this form of expression); and the depth of his experience is determined by the number of $B s$ he has witnessed. He differs from the man of knowledge in that his universal judgment is limited to past, observed, cases of A's holding of B. On the other hand, Met A I, 981a5-9, suggests that the man of experience simply remembers many propositions of the form 'This $B$ is A' ('Socrates was cured of fever by taking hellebore'), and does not formulate any general proposition. The distinction between these two ways of taking 'experience' is not perhaps very great: each seems to provide a perfectly reasonable account of what it is to rely on experience".

32 Cf. Segundos Analíticos I 18.

${ }^{33}$ Cf. Segundos Analíticos II 19 100b 1-5.
} 
faz com que alguns descubram um universal quase que imediatamente. ${ }^{34}$ Essa vivacidade pode ser exercitada e a dialética serve para esse propósito. ${ }^{35}$ A capacidade de perceber, em um único golpe, seja o universal presente em um caso particular, seja a hipótese verdadeira em detrimento da falsa, é uma disposição natural, e essa disposição natural é uma capacidade certa de escolha. Assim é que um observador perspicaz conhece a instância universal no particular percebido. É por isso que, às vezes, não é suficiente, para induzir, observar todas as ocorrências particulares possíveis de uma classe. Antes, é suficiente que a análise se detenha em alguns casos ou mesmo em um caso específico e paradigmático, já que o universal se encontraria presente nesse caso exemplar. $O$ ponto decisivo está na capacidade do observador. Além disso, há que se levar em conta a natureza do objeto e a inteligibilidade possível de se ter com relação a tal objeto. Dessa forma, o número de observações necessárias em uma indução varia dependendo da natureza do objeto que se está investigando. ${ }^{36}$ Por isso, não causa estranhamento que o número de observações necessárias para concluir universalmente, via método indutivo, não seja um problema.

Se essa análise estiver correta, através da indução - que necessita da percepção - percebe-se o universal nos particulares. Nesse momento entra

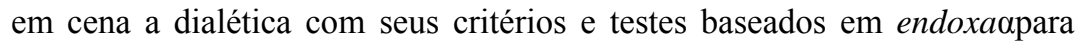
que, então, os primeiros princípios possam ser apreendidos de forma inequívoca pela inteligência (nous), disposição responsável por conhecer os princípios. A dificuldade ainda não devidamente elucidada, a meu ver, é que ora Aristóteles diz que é através da percepção que, quando se percebe o particular, já se percebe o universal no particular, ora diz que é através da experiência (ou melhor, da repetição da experiência) que se obtém esse

\footnotetext{
${ }^{34}$ Cf. Segundos Analíticos I 34 89b 10.

35 Cf. Tópicos, VIII 14, 163b 10-15.

36 Segundo Ross (1987, p. 49-50), a natureza do objeto é, inclusive, o único critério que se deve utilizar no tocante a saber quantas observações são necessárias à indução, não havendo referência alguma à capacidade do observador: "Se considerarmos os argumentos atuais apresentados por Aristóteles e descritos como indutivos, vemos que vão da indução perfeita aos argumentos nos quais uma regra geral é suportada por referência a apenas um exemplo. A natureza da indução parece ser, para ele, a possibilidade de uma pessoa ser 'guiada' por outra, de um conhecimento particular para um universal. A necessidade de um, de poucos, de muitos ou de todos os exemplos depende da inteligibilidade relativa da matéria à qual se aplica. Quando afirma que os primeiros princípios da ciência são apreendidos por indução ou por percepção, Aristóteles não pretende afirmar residirem aí os métodos fundamentalmente diferentes de os apreender. Quando a forma é facilmente separada no pensamento da matéria, tal como na matemática, o espírito passa da percepção da verdade num exemplo isolado à certeza de sua aplicabilidade a todos os casos semelhantes; quando a forma é mais difícil de separar da matéria, uma indução fundada em muitos exemplos torna-se necessária." Entendo que ambas são necessárias: capacidade do observador e natureza do objeto.
} 
conhecimento do universal no particular observado e ora diz que é através da indução que se pode perceber, em uma enumeração de casos particulares, algo único que se repete em toda essa enumeração. ${ }^{37}$

No que tange à relação entre percepção e universal, diz Aristóteles em Segundos Analíticos II 19 100a 15-100b 5 que quando se percebe um humano qualquer se percebe igualmente que ele é um homem (a classe ou o universal a que pertence, por força de sua essência). ${ }^{38}$ Entretanto, a percepção é sempre de um particular inserido em um lugar e em um tempo. ${ }^{39}$ A percepção possibilita que o que é percebido se torne impressão que, repetida, se fixe na memória gerando a experiência (empeiria). A experiência possibilita que se capte o universal em cada uma das coisas particulares observadas, mas a experiência só é possível por causa da percepção. Assim, o que se vê é Cálias, mas é possível, também, perceber o humano em Cálias, o animal no humano, etc., entretanto, não apenas pela sensação. Vemos o particular, mas percebemos, pela razão, aquilo que o particular compartilha com todos os outros elementos que lhe são semelhantes, e passamos, assim, de um movimento de universalidade primário a outros mais extensos, mais amplos.

Se minha análise até aqui estiver correta, então percepção, experiência e indução são: i. relacionados, no sentido em que a indução depende da experiência e a experiência depende da percepção e ii. etapas ou estágios de conhecimento sendo a percepção a mais rudimentar ou primária e a indução a mais desenvolvida e mais próxima do resultado que se quer alcançar (ainda que, para uma completa e correta apreensão dos princípios, seja indispensável a dialética e o nous). Assim, a partir de muitas

${ }^{37}$ Barnes, em comentário à tradução dos Segundos Analíticos (2002, p. 266), explica a questão da seguinte forma: "the process Aristotle describes produces universals; but it starts from perception and perception is of particulars - how, then, can the gap between particulars and universals be jumped? Aristotle's answer is that perception in fact give us universals from the start (cf. A 31, 87b29, notes). He means that we perceive things as As; and that this, so to speak, lodges the universal, $A$, in our minds from the start - although we shall not, of course, have an explicit or articulated understanding of $A$ until we have advanced to Stage (D)".

${ }^{38}$ É, também, o que entende Ross (1949), em comentário aos Segundos Analíticos: "This is made easier to understand by the fact that even at na earlier stage - that of perception - the awareness of an individual is at the same time awareness of a universal preesent in the individual; we perceive an individual thing, but what we perceive in it is a set of qualities each of which can belong to other individual thing." (p. 678).

${ }^{39}$ Como, aliás, esclarece Zingano (1998): "Aristóteles não está dizendo que a sensação tem por objeto 0 universal; é doutrina bem estabelecida no aristotelismo que a sensação tem por objeto o particular. 0 que ele assinala é que a sensação (humana) se dá sempre no contexto do reconhecimento do universal. (...). A percepção é sempre de particulares, mas, ao mesmo tempo, ela corresponde (no caso humano) a universais; apreender algo a título de universal é, no entanto, uma operação de reconhecimento feita pela razão e não pela sensação". (p. 66). 
impressões sensíveis algo se fixa na memória constituindo uma única experiência e produzindo um conceito (nous). É como se as muitas percepções caóticas e sensíveis, em um determinado momento, se detivessem na alma ou ficassem retidas de forma ordenada, produzindo o universal. Com a memória e a experiência tem início esse processo de fixação, de cristalização, o qual possibilita os universais a partir da apreensão dos particulares retendo o que há de idêntico nos vários individuais percebidos. ${ }^{40}$

Há uma expansão do conhecimento nas passagens de uma a outra instância, i.e. da percepção à experiência e da experiência à indução. Esse conhecimento que se expande se refere ao conhecimento do universal no particular, e.g. do humano em Cálias, do animal no humano, do que é vivo no animal, etc. É assim que parece clara e coerente a analogia que Aristóteles apresenta entre o conhecimento desorganizado e múltiplo, propiciado pela percepção sensorial advindo das sensações, o qual vai se tornando organizado e unificado, com a cena dos soldados inicialmente desordenados e, na sequência, novamente ordenados. No conhecimento dos princípios, basta que uma observação particular (a qual cai sob um universal) se fixe na alma para que, pouco a pouco, com o auxílio da experiência, da indução e da razão intuitiva, um conhecimento ordenado comece a se formar.

A relação entre particular e universal não é tão simples como pode parecer e não foi ainda suficientemente analisada. É provável, inclusive, que seja um dos pontos de mais difícil compreensão no tocante ao pensamento de Aristóteles. O próprio Aristóteles considerou tal relação uma das questões mais difíceis subjacentes à problemática do conhecimento, entretanto absolutamente necessária. ${ }^{41}$ É possível ter o conhecimento de um universal sem o conhecimento dos particulares (alguns ou todos ou pelo

\footnotetext{
40 É bem provável que essa discussão encontre maior fecundidade à luz de uma análise cuidadosa do De Anima, como, por exemplo, para avaliar se esse universal é apenas acessado ou se ele é produzido pela razão. Entretanto, o objetivo desta tese é analisar a temática do conhecimento em Aristóteles nos Analíticos, Tópicos, Metafísica, Refutações Sofísticas e Retórica. Zingano (1998), por exemplo, afirma que, no De Anima, segundo Aristóteles, "não há nenhum universal real que possa afetar o entendimento, pois só existem indivíduos, embora o universal produzido pela razão a partir dos dados obtidos pela percepção dos indivíduos tenha de corresponder a algo de re e não somente de dicto". (p. 23). E ainda que, no De Anima, há a tese de que "os universais não se formam na alma através do repouso do movimento causado pelas afecções sensíveis, mas são o produto da atividade da razão, que os engendra a partir do que é dado na sensibilidade" (p. 27). E ainda que "separar (pela razão) ou produzir os universais significa propriamente 0 ato pelo qual tomamos certas propriedades como universais a respeito de certos indivíduos, demarcando-os desta forma de todos os outros." (p.26).

${ }^{41}$ Cf. Métafísica $\beta 4$ 999a 25-30.
} 
menos um), os quais são englobados por ele? E o conhecimento dos particulares sem o conhecimento do universal no qual os particulares estão contidos, é possível? Existe uma ordem na aquisição de um e de outro?

Em Primeiros Analíticos II 21, encontra-se um trecho esclarecedor sobre a relação entre particular e universal. Opto por reproduzir o argumento na íntegra, para que se obtenha uma visão abrangente da questão:

Seja A significando dois ângulos retos, $\mathrm{B}$ triângulo, e $\Gamma$ triângulo sensível. Se pode julgar, com efeito, que $\Gamma$ não existe, conhecendo que todo triângulo tem dois ângulos retos, de tal sorte que se conhecerá e se ignorará ao mesmo tempo a mesma coisa. Porque a expressão saber que todo triângulo tem seus ângulos iguais a dois retos não é algo simples: ela significa tanto o conhecimento geral, quanto o conhecimento particular. Assim, pois, se tem o conhecimento geral que $\Gamma$ tem dois ângulos retos, mas não se tem o conhecimento particular disso; por consequência, não se terá um conhecimento e uma ignorância contrários um ao outro. - Se pode criticar da mesma maneira o argumento do Mênon, segundo o qual o conhecimento é uma reminiscência. Não ocorre jamais, com efeito, que se tenha conhecimento anteriormente ao particular, mas ao mesmo tempo que tem lugar a indução nós adquirimos a ciência das coisas particulares, como se nós não fizéssemos mais que reconhecer. É que há certas coisas [particulares] que nós conhecemos imediatamente, por exemplo que os ângulos [desse triângulo particular] são iguais à dois retos, desde que saibamos que ele seja um triângulo. (Primeiros Analíticos II 21 67a 10-25).

O silogismo é o seguinte:

Todo triângulo tem dois ângulos retos

Isto é um triângulo

Isto tem dois ângulos retos.

Nesse caso, é possível conhecer a primeira premissa e não a segunda, i.e. é possível a alguém saber que todos os triângulos possuem dois ângulos retos, mas não saber que uma figura específica qualquer seja um triângulo, caso em que ele saberá e não saberá a mesma coisa, mas sob aspectos 
diferentes: saberá, nesse caso, sob o aspecto universal, mas não sob o aspecto particular de um triângulo específico. Por outro lado, é possível que alguém, ao conhecer a figura de um triângulo específico, saiba que seus ângulos são iguais a dois retos, mas não que todos os triângulos tenham dois ângulos retos. Em ambos os casos, o conhecimento é imperfeito e admite erros. No segundo caso é fácil identificar o problema, pois, estando de posse apenas do conhecimento particular, não se tem conhecimento científico, não se sabe a causa. $O$ primeiro caso, aquele em que alguém tem $o$ conhecimento do universal, mas não do particular, também está sujeito ao erro. ${ }^{42} \mathrm{O}$ conhecimento científico só é adquirido de forma completa quando ambas as premissas são conhecidas e, acrescente-se, quando as premissas são mais conhecidas que a conclusão que delas deriva. Nesse caso, tem-se o conhecimento tanto do particular quanto do universal e não de forma isolada, mas correlacionada: dos particulares que levam a um universal e de um universal que se aplica a todos os particulares.

É interessante perceber que a referência de Aristóteles a essa difícil relação entre o particular e o universal, em Segundos Analíticos, aparece, exatamente como em Primeiros Analíticos, em um trecho onde o exemplo utilizado é o do triângulo. O argumento apresentado em Segundos Analíticos é o seguinte:

É possível conhecer quando algumas coisas são conhecidas anteriormente, e que outras o são no momento mesmo onde se adquire este conhecimento, a saber todas aquelas que se encontram sob um universal do qual se tem conhecimento. Com efeito, que todo triângulo tem seus ângulos iguais a dois retos sendo conhecido anteriormente, mas que esta figura inscrita em um cemicírculo seja um triângulo se conhece ao mesmo tempo que se infere a conclusão (...). Antes de ter inferido ou de ter um silogismo, é preciso talvez dizer que de um certo modo se conhece cientificamente, e de um outro modo não. Porque disto que não se sabia em sentido absoluto se existia, como se poderia saber em sentido absoluto que seus ângulos valem dois ângulos retos? Mas é claro que se conhece cientificamente desta maneira: se conhece cientificamente o universal, mas não se conhece cientificamente em sentido absoluto. De outro modo, se seguiria a dificuldade de Mênon: ou não se aprende nada, ou se aprenderá o que já era sabido. (I 171 a 15-30).

${ }^{42}$ Cf. Metafísica A 1 981a 20-25. 
O primeiro ponto a ser levantado na interpretação da relação entre particular e universal é que o conhecimento prévio, necessário a qualquer argumento é necessário em dois sentidos: quanto à essência e quanto à existência. É possível ter conhecimento prévio apenas de um deles e é possível ter o conhecimento prévio de ambos. Todavia, entende-se que, no que se refere ao conhecimento completo ou à unidade de tal conhecimento, ela só é possível quando se conhece tanto que algo é, quanto o que ele é, i.e. tanto a existência, quanto a essência. Mas o conhecimento do o que é algo admite diferentes graus, do mais rudimentar ao mais elevado e completo. É apenas quando se conhece o que uma coisa é no seu grau mais elevado que se obtém a essência que lhe é própria. O nível mais elementar, por outro lado, se refere à definição de tipo nominal, aquela que apenas diz o que o nome significa. Todavia, esse nível, ainda que rudimentar, é necessário ao conhecimento, pois todo conhecimento pressupõe um saber prévio. Assim, pode-se afirmar o percurso do conhecimento como algo que principia pela percepção - e a percepção é sempre do particular - mas que já contém em si, em potência, a possibilidade do universal: um universal vago, certamente, abstrato e genérico; um universal que apresenta algo da essência, mas não a essência propriamente dita. O conhecimento prévio é um conhecimento mínimo do objeto, mas suficiente para uma inicial identificação. Tal conhecimento mínimo se refere ao conhecimento de que o objeto existe e ao conhecimento de algo sobre o que ele é, i.e. algum elemento de sua essência.

O segundo ponto relevante é que, no exemplo, é possível conhecer o universal "todo triângulo tem dois ângulos retos" e desconhecer o particular "esta figura, inscrita nesse semicírculo, é um triângulo". Assim é que se conhece em um sentido (universal) e se desconhece em outro (particular). A conclusão do argumento seria algo como "esta figura, inscrita nesse semicírculo, tem dois ângulos retos". Trata-se da passagem de um conhecimento universal para sua atualização em um particular. A conclusão, nesse caso, resulta de uma premissa maior, universal e previamente conhecida, pois faz parte do conhecimento prévio, e uma premissa menor, particular e desconhecida, que se torna conhecida ao mesmo tempo em que se conhece a conclusão. É nesse jogo entre particular e universal que a teoria aristotélica do conhecimento está fundamentada e, dessa forma, se pode conhecer e não conhecer algo, mas sob aspectos diferentes. Assim, na busca pelos princípios próprios, cada ciência coleta por meio da percepção um saber prévio que, ao ser elaborado, permite que 
se obtenham os princípios de cada ciência. A percepção é o ponto de partida do acesso de cada ciência específica aos seus princípios próprios. ${ }^{43}$

Parece, no entanto, que a necessidade da percepção $-\mathrm{e}$, posteriormente da indução - e da dialética pode variar de acordo com as ciências. Muitas ciências encontram na observação de fatos o material inicial para sua investigação; todavia os testes dialéticos apresentados nos Tópicos são, igualmente, necessários. Na esfera da ética, por exemplo, o recurso à indução é muito menor, por serem escassas e vagas as observações às quais se tem acesso. Em casos desse tipo, há que se privilegiar as opiniões reputadas já existentes sobre o assunto em questão. É assim que se compreende como Aristóteles ora atribui a descoberta dos princípios ao método indutivo, ora à dialética. Todavia, é digno de nota que a experiência se embasa nas opiniões da maioria ou dos mais sábios, as quais se tornam opiniões aceitas, que foram construídas com base nas observações particulares, sendo, assim, tanto partícipes do processo dialético como do indutivo.

A indução é, sem dúvida, indispensável na obtenção do conhecimento dos primeiros princípios. Entretanto, poder-se-ia pensar que, por conta da fragilidade epistêmica de tal método, a indução seria, nessas condições, insuficiente e que, por isso, Aristóteles introduziria o nous como a faculdade intuitiva imediata, capaz de corrigir os problemas da indução na aquisição do conhecimento dos primeiros princípios. Mas esse não parece ser o caso. O conhecimento produzido indutivamente já é do universal. Não se encontra, em Aristóteles, a afirmação que o nous viria, no processo do conhecimento dos princípios, corrigir as possíveis falhas da indução. Aliás, é difícil encontrar em Aristóteles uma crítica ao método indutivo no tocante à sua fragilidade epistêmica, o que, hoje, causa certo estranhamento, pois parece inegável que um argumento indutivo não é um argumento válido, dado que a verdade das premissas não garante a verdade da conclusão. Ainda que a indução pareça um argumento frágil, pois a mera enumeração exaustiva dos casos particulares verificados como verdadeiros não garante a verdade da conclusão, Aristóteles não critica a indução, pelo menos não como método do nous. A questão parece, antes, de outra ordem: percepção, experiência, indução, dialética e inteligência intuitiva são âmbitos de

\footnotetext{
43 De acordo com Zingano: "O que é decisivo na tese aristotélica, e que projeta para além do mundo grego o problema que ela finalmente formula, é a tese que a faculdade intelectiva, trabalhando unicamente com os dados sensíveis, apreendidos pela sensação mediante afecção e reproduzidos pela imaginação, tem a virtude de apanhar o ser da coisa mesma para além de suas formas ou qualidades sensíveis." (1998, p. 20).
} 
aspectos distintos e, por isso mesmo, não concorrem uns com os outros como ocorre, por exemplo, na relação existente entre nous e episteme.

\section{III}

É possível ver de que modo e em que medida a dialética e a indução, ou a dialética em sua parte indutiva auxilia o acesso aos indemonstráveis. Entretanto, há outro elemento fundamental nesse acesso que ainda não foi abordado mais incisivamente: trata-se daquela faculdade da alma (nous) por meio da qual, segundo Aristóteles, são apreendidos por intuição os primeiros princípios. Ora, como conciliar aquele âmbito indutivo do método dialético com tal inteligência intuitiva (nous) - aparentemente tão distintos um do outro, no tocante à apreensão dos princípios?

Aristóteles menciona o conhecimento anapodíctico em Segundos Analíticos, pela primeira vez, contrapondo-o ao conhecimento apodíctico, quando diz, após caracterizar o silogismo científico, que, se há outro método de conhecer, ele será visto mais a frente. O trecho é o seguinte: "Nós pensamos conhecer cientificamente cada coisa em sentido absoluto (...) quando pensamos conhecer a causa do fato pela qual a coisa é (...) e que esta coisa não pode ser de outro modo. É claro que o saber científico é alguma coisa deste tipo (...). Se existe um outro gênero de saber, nós o diremos mais tarde". (I 2 71b 10-20). Que esse "outro gênero" não é o científico, é óbvio; que ele, por isso, seja anapodíctico, também fica claro, tendo em vista que científico é o conhecimento que resulta de silogismo demonstrativo. Mas a que outro tipo de conhecimento Aristóteles está aludindo? A sequência do texto indica, imediatamente, que tal conhecimento se refere ao modo pelo qual conhecemos as primeiras premissas, as quais devem ser verdadeiras, primeiras, imediatas, mais conhecidas que a conclusão, anteriores à conclusão e que sejam causas desta. Já se viu que tais premissas são os princípios próprios. A segunda referência ao conhecimento anapodíctico aparece não muito distante da primeira e é a seguinte: "E nós dissemos que há não apenas ciência, mas também um princípio de ciência, pelo qual nós conhecemos os termos últimos." (I 3 72b 20). Então, para além da ciência demonstrativa, há um tipo de conhecimento indemonstrável, superior e anterior ao demonstrável, a saber, aquele dos primeiros princípios, premissas imediatas da demonstração. ${ }^{44}$ Um tipo de "princípio de ciência" através do qual o

${ }^{44}$ Cf. Segundos Analíticos I 22 84a 30. 
conhecimento científico torna-se possível. Tal "princípio de ciência"45 é o voǔs. No final dos Segundos Analíticos, Aristóteles afirma o seguinte: "No que concerne ao silogismo e a demonstração, ao que cada um deles é e como se produzem, está claro, e também ao que concerne à ciência demonstrativa. Porque são a mesma coisa. Mas no que concerne aos princípios, como eles vem a ser conhecidos e qual é a faculdade que os faz conhecer, isso ficará claro ao se examinar primeiro algumas dificuldades". (II 19 99b 15).

Há duas questões importantes nessa passagem: como chegamos a conhecer os princípios e qual é a faculdade (hexis) responsável por tal conhecimento. A resposta à primeira questão compreende aquele percurso formado pela percepção sensível, pela memória, pela experiência e que encontra seu método na indução. ${ }^{46}$ A resposta à segunda pergunta é o nous. São respostas diferentes não porque Aristóteles seja obscuro ou ambíguo no tocante à apreensão dos princípios imediatos, mas simplesmente porque se referem a coisas que são, elas próprias, diferentes. Assim como a ciência é resultado de método demonstrativo e, por tanto, mediado, de coisas que admitem demonstração, a intuição é conhecimento imediato e indemonstrável dos princípios pelos quais se torna exequível a demonstração.

Imediatamente na sequência do texto, Aristóteles afirma que, na busca da verdade, dos meios que utilizamos, alguns sempre possibilitam um conhecimento verdadeiro, outros não. Dos que sempre possibilitam conhecimento verdadeiro um é o conhecimento científico e outro é a intuição (nous). Muito já se disse sobre a questão de que o conhecimento dos primeiros princípios não é conhecimento científico (pois o princípio da demonstração não é, ele mesmo, demonstração), e parece claro, igualmente, que não pode ser por um dos meios que incorrem em erro que se obtém o conhecimento dos primeiros princípios. Bem, tendo em vista que o conhecimento científico deve partir de premissas mais conhecidas que a conclusão, resta evidente, por não haver outra instância mais perfeita e infalível que o conhecimento científico a não ser a intuição, que seja por ela que os primeiros princípios possam ser conhecidos. O nous, diz Aristóteles, busca a verdade e nunca incorre em erro e é por meio dele que se torna possível a apreensão dos princípios indemonstráveis. ${ }^{47}$

Haveria em tal processo de aquisição dos princípios próprios um momento que configuraria aquele instante - de difícil conceituação - em

45 Cf. Segundos Analíticos I 33 88b 35.

${ }^{46}$ Cf. Segundos Analíticos II 19 100a 5-10.

${ }^{47} \mathrm{Cf}$. Segundos Analíticos II 19 100b 10-15. 
que nos vários casos particulares se vê o que há de universal em todos eles, o elemento que todos eles partilham ou teriam em comum, mas de forma imediata, não discursiva, intuitiva. Aquele que conhece, por um ato intuitivo do intelecto, consegue captar na multiplicidade dos singulares, o uno, o universal. É por meio do voũ que se apreende o que há de universal em todos aqueles casos particulares observados, captando o princípio como algo necessário e básico e assegurando a "garantia epistêmica" de que o princípio é verdadeiro. Tal faculdade é infalível e vê o universal no particular, enquanto causa ou princípio deste e é por ele que os princípios são conhecidos de modo não discursivo, não argumentativo, mas imediato. Quando o processo crítico dialético de ascensão aos princípios próprios, operado por sua esfera indutiva, consegue atingir tais indemonstráveis, os problemas e erros possíveis de ocorrerem - tendo em vista que o processo se inicia com a percepção - são suprimidos. Tal supressão ocorre pelo exame dialético. O nous, por outro lado, opera de forma segura, infalível e irrefutável, intuindo os indemonstráveis. E é a partir dos indemonstráveis que a ciência elabora aquele tipo de conhecimento necessário do qual não pode haver persuasão contrária, que é verdadeiro e que não pode ser de outra forma.

\section{IV}

A percepção é necessária ao conhecimento dos primeiros princípios, mas não suficiente. O processo segue com a memória, com a experiência, e, por meio da indução, da dialética e com o auxílio do nous, chega-se ao conhecimento dos princípios. A indução e a dialética se caracterizam como o caminho preparatório mediado pela percepção, que possibilita a intuição do universal nos particulares de forma imediata. A inteligência intuitiva completa a lista de itens necessários e suficientes para o acesso aos princípios próprios de cada ciência. É certo, também, que a participação de cada um desses âmbitos é diferente dependendo de cada caso. As ciências não são todas iguais, nem em seus objetos de estudo, nem em seu rigor, tampouco em seu método.

Dessa forma, os primeiros princípios próprios indemonstráveis necessários a todas as ciências são proposições fundamentais apreendidas por um processo dialético em que se conjuga indução e intuição (nous). Os primeiros princípios são indemonstráveis por se configurarem em um tipo de explicação - acerca de um fenômeno qualquer e dentro de um gênero específico de conhecimento - que não necessita, por sua vez, ser explicado. E não necessita porque não existe explicação possível, pois os primeiros 
princípios próprios são aquelas explicações básicas e elementares dentro de uma ciência qualquer das quais todas as outras coisas (mais cognoscíveis para nós), são derivadas e explicadas. Assim é que, no tocante aos princípios próprios, são investigados e discutidos os assuntos que são peculiares a cada ciência.

A diferença referida por Aristóteles ao atribuir ora à dialética, ora à indução, ora à inteligência intuitiva a aquisição dos primeiros princípios se deve ao fato de serem instâncias distintas, mas complementares, cada qual com sua função: a percepção, como disposição inata através da qual se acessa o particular e que torna a experiência possível; a experiência, como capacidade por meio da qual se produz um alargamento do conhecimento advindo da percepção; a indução, como o método pelo qual conhecemos o universal por meio de particulares; a dialética, como instrumento metodológico pelo qual se investiga um problema qualquer, auxiliando na busca pelos princípios, mais especificamente, pelas definições; o nous, como faculdade, movimento noético que opera de forma segura, infalível e irrefutável, intuindo os indemonstráveis.

\section{Referências}

ARISTÓTELES. De Anima. Apresentação, tradução e notas de Maria Cecília Gomes dos Reis. São Paulo: Ed. 34, 2006.

. Éthique à Nicomaque. Nouvelle Traduction avec introduction, notes et index par J. Tricot. Paris: Librairie Philosophique J. Vrin, 1997.

. Física I e II. Prefácio, tradução, introdução e comentário de Lucas Angioni. São Paulo: Unicamp, 2009.

. Les Premiers Analytiques. Traduction nouvelle et notes par J. Tricot. Paris: Librairie Philosophique J. Vrin, 1966.

. Les Topiques. Traduction nouvelle et notes par J. Tricot. Paris: Librairie Philosophique J. Vrin, 1997.

. Posterior Analytics. Translated with a Commentary by Jonathan Barnes. Second Edition. Oxford: Clarendon Press, 2002.

Secondes Analytiques. Introduction, traduction, notes, bibliographie et index par Pierre Pellegrin. s/l: GF Flammarion, 2005.

. Les Réfutations Sophistiques. Traduction nouvelle et notes par J. Tricot. Paris: Librairie Philosophique J. Vrin, 1995.

. Métaphysique. Nouv. éd. Paris: Librairie Philosophique J. Vrin, 1953. v. 1 e 2 (Bibliothèque des textes philosophiques). 
. Topics: Books I and VIII with excerpts from related texts. Translated with a Commentary by Robin Smith. Oxford: Clarendon Press, 2003.

AUBENQUE, P. Le problème de l'être chez Aristote. Paris: PUF, 1962.

BERTI, E. Novos estudos aristotélicos I: epistemologia, lógica e dialética. São Paulo: Loyola, 2010.

GUÉROULT, M. "Logique, argumentation et histoire de la philosophie chez Aristote". In: La théorie de l'argumentation. Louvaine/Paris: Centre National Belge de Recherches de Logique, p. 431-449, (s/d).

LE BLOND, J. M. Logique et méthode chez Aristote: étude sur la recherche des principes dans la physique aristotélicienne. Paris: J. Vrin, 1939.

PELLEGRIN, P. Le vocabulaire d'Aristote. Paris: Ellipses, 2009.

PORCHAT. Ciência e dialética em Aristóteles. São Paulo: Ed. Unesp, 2001.

ROSS, Sir D. Aristotele's Prior and Posterior Analytics a revised text with introduction and comentary. London: Oxford Clarendon Press, 1949.

. Aristóteles. Lisboa: Publicações Dom Quixote, 1987.

VERBEKE, G. "Philosophie et conceptions préphilosophiques chez Aristote". Revue Philosophique de Louvain. Troisième série, Tome 59, n. 63, 1961, p. 405-430. Disponível em: http://www.persee.fr/web/revues/home/ prescript/article/phlou003538411961Acesso em: 28 maio 2012. ZINGANO, M. Razão e sensação em Aristóteles: um ensaio sobre De Anima III, 4-5. Porto Alegre: L\&PM, 1998. 